\title{
Uma visão sociológica sobre a violência doméstica: o combate à violência de genêro
}

\author{
Una visión sociológica sobre la violencia doméstica: \\ el combate contra la violencia de género \\ A sociological view on domestic violence: the fight against gender
}

\begin{abstract}
RESUMO
O presente estudo tem como finalidade apresentar uma breve explanação sobre a violência contra a mulher e sua subordinação ao homem, sob uma perspectiva sociológica (já que, essa discriminação e tratamento inferior dado à mulher nada mais é do que uma verdadeira construção histórico-cultural); bem como demonstrar como é realizado seu enfrentamento no Brasil, levando em consideração orientações de cunho mundial.
\end{abstract}

\section{PALAVRAS-CHAVE}

Violência doméstica, Violência contra a mulher, Empoderamemnto, Formas de discriminação.

\section{RESUMEN}

Este estudio tiene como objetivo presentar una breve explicación sobre la violencia contra la mujer y su subordinación a los hombres, bajo una perspectiva sociológica (ya que la discriminación y el trato de inferioridad de la mujer no es más que una verdadera construcción histórica y cultural), y demostrar cómo se manifiestan las formas de discriminación en Brasil, teniendo en cuenta las directrices de carácter mundial.

\section{Palabras clave}

Violencia doméstica, Violencia contra la mujer, Empoderamiento, Formas de discriminación.

\begin{abstract}
This study aims to present a brief explanation on violence against women and their subordination to men, under a sociological perspective (since this discrimination and inferior treatment of women is nothing more than a true historical and cultural construction); and demonstrate how it is done your face in Brazil, taking into consideration guidelines of global nature.
\end{abstract}

\section{KEYWORDS}

Domestic violence, Violence against women, Empowerment, Forms of discrimination. 
INTRODUÇÃO

O presente trabalho tem como finalidade precípua fazer uma análise da violência contra a mulher, a qual se desdobra em sexual, física e emocional, sob uma perspectiva sociológica, chegando, após ferrenha luta da mulheres, à forma como a violência de gênero é combatida no Brasil, ressaltando que se trata de assunto discutido mundialmente, e que se dá, principalmente, em razão da persistente discriminação contra a mulher desde os primórdios.

A violência contra a mulher e sua subordinação ao homem se deu através de uma construção cultural, uma vez que, desde os primórdios a mulheres eram excluídas, possuíam o "dever" da procriação e não exerciam, em campo algum, nenhum papel relevante para si e para a sociedade. Essa afirmação se confirma nos casamento que eram celebrados em Roma, onde o marido exercia poder ilimitado sobre a mulher e era realizado sem nenhuma afeição.

Em razão dessa violência sofrida constantemente pelas mulheres, houve a necessidade de se garantir e efetivar os direitos mais inerentes a esse gênero, qual seja, a vida plena, sem violência e com medidas permissivas para punição de supostos agressores, porém, foi uma longa caminhada até se chegar a elaboração de uma lei, no Brasil, que visasse coibir a violência contra a mulher.

A nível mundial essa proteção e enfrenta- mento à violência de gênero se deu com a Convenção Sobre a Eliminação de Todas as Formas de Violência Contra a Mulher, a qual foi adotada pela Organização das Nações Unidas em 1979 e que, apesar de não conter pontos específicos sobre a violência contra a mulher, fez com que o Comitê da ONU sobre eliminação de todas as formas de discriminação contra a mulher, exarasse recomendação referente a essa violência de gênero, foi um dos primeiros documentos que tratou da mulher, o qual foi fruto de uma reivindicação ferrenha dessa classe.

Criou-se, também, a Convenção Interamericana para Previnir, Punir e Erradicar a violência contra a mulher, de 1994, documento de cunho mundial e que afirma que a violência contra a mulher constitui uma forma de desrespeito e violação aos denominados direitos humanos.

Assim, a violência contra a mulher é toda aquela realizada comissiva ou omissivamente e que cause qualquer tipo de dano, morte, sofrimento físico, psicológico, sexual à muIher, podendo ser tanto no âmbito público quanto no privado (Convenção de Belém do Pará). Porém, insta salientar que, mesmo com essa norma de cunho mundial, o Brasil ainda permaneceu inerte e omisso durante muitos anos, só vindo a coibir a violência doméstica com advento da Lei Maria da Penha, a qual, mesmo sendo criada para prevenir a violência de gênero ainda demonstra pouca eficácia. 
O presente estudo tem como finalidade apresentar uma breve explanação sobre a violência contra a mulher sob uma perspectiva sociológica, bem como demonstrar como é realizado seu enfrentamento no Brasil, levando em consideração orientações de cunho mundial. Para a compreensão do trabalho será apresentada a situação atual da mulher no cenário social e quais os motivos que levam as mulheres a se submeterem e sofrerem violência doméstica, seja ela verbal, física ou sexual, a luta contra a violência de gênero, e, por fim o desdobramento da segurança concedida à mulher após uma "luta" cultural para seu reconhecimento como verdadeiro sujeito de direito, como forma de minimizar essa problemática que, de ser tão recorrente, passou a ser combatida mundialmente.

\section{Entendendo a história do Brasil}

A História do Brasil sempre esteve propensa à violência de forma muito forte. Essa prática, que começa com a escravização dos povos indígenas e africanos, é o resultado do efeito perverso das desigualdades sociais com as quais fomos colonizados. Suas origens estão firmemente enraizadas na formação patriarcal, sexista, homofóbica, intolerante e escravista-socialista, da sociedade brasileira, herdeira da colônia portuguesa.

No Brasil de hoje todo tipo de violência encontra-se proibida e é objeto de punição, exceto para preservar a própria vida. No entanto, na prática, essas limitações não são obedecidas.
Em todas as camadas socias as pessoas estão expostas a diversos tipos de violência: urbana, no campo, o bullying nas escolas, os assédios morais. Isso significa que o enfrentamento à violência está além da punição, exige articulação e mobilização de ações conjuntas, efetivas para se trabalhar a prevenção, denúncia, assistência e proteção. É muito mais um trabalho de conscientização, mudança de comportamento e mentalidade, por estar enraizada em nossa dinâmica de reprodução e produção de valores.

Ao longo da nossa história o uso da violência tem sido praticado pelos ditadores, chefes de Estado moderno, maridos e religiosos. Legitimada muitas vezes pela ideologia religiosa, a violência doméstica, que ocorre no espaço sagrado dos lares, deixa de ser vista por adquirir uma caráter dual: divino e terreno, onde se afirma que as mulheres devem ser submissas ao seus maridos, levando o conceito de submissão aos raios do conceito de subserviência, subalterninade e perda da dignidade humana.

Nos dias de hoje, com o advento da Lei Maria da Penha, que criminaliza a violência doméstica, começa a delinear-se uma esperança, pois por séculos fomos massificados com conceitos que diziam que em briga de marido e mulher não se mete a colher, e assim assistíamos passivamente mulheres violentadas em todos os seus direitos. Não há muito tempo, cerca de vinte anos, as mulheres brasileiras não tinham direto a terem seus próprios CPFs, utilizando o do seu marido e, 
quando do casamento, se obrigavam a retirar naturalmente o sobrenome do pai e colocar o do marido, caracterizando simbolicamente que estava mudando de "dono".

Nos crimes passionais havia uma dupla moralidade de julgamento: um para o homem, que podia utilizar o conceito de "legitima defesa da honra" e para o mesmo crime as mulheres que eram condenadas por descontrole emocional.

Casos clássicos foram o de Doca Street, que assassinou sua companheira Ângela Diniz, por ciúmes, antes permanecendo com ela em cárcere privado, chagando a ser absolvido "por legitima defesa da honra" e de Dorinha Duval, atriz da globo, casada com companheiro bem mais novo que a humilhava chamando-a de velha e fazendo comentários pejorativos sobre seu corpo e idade, comparando-a a suas amantes mais novas e agredindo-a fisicamente. Não mais agüentando, ela o assassina: por ciúmes e extrema violência física e mental. Foi condenada a trinta anos de prisão. Crimes semelhantes, nos anos 70, resultados diferentes, por se tratar da dupla moralidade existente, construção histórica e cultural da inferioridade da mulher.

Surge, assim, a necessidade de combate a esse tipo de violência, havendo, então, lutas para o enfrentamento à violência de gênero.

\section{Da luta contra violência de gênero}

Uma vez o filósofo Grego Aristóteles afirmou que onde há luta há também vitória. Se for pensado contextualmente verificar-se-á que as mulheres, no Brasil especificamente, têm conquistado espaços cada vez maiores dentro do mercado moderno de trabalho e se empoderado em sua própria defesa contra a opressão do patriarcalismo secular, que a violenta historicamente. Mas no âmbito da luta pela igualdade de gênero estamos longe de uma vitória definitiva.

O Brasil hoje não mais é apontado pela Sociedade Mundial como o país que mais sofre violência doméstica, mas ainda temos muito que conquistar neste terreno específico.

Focando o Estado Pernambuco, verifica-se que em 2010 tivemos 245 mulheres mortas vitimizadas pela violência de seus companheiros. Desta forma far-se-á uma análise das mudanças acontecidas, após a criação da Lei Maria da Penha, um grande avanço no enfrentamento à violência doméstica contra a mulher, por focar a violência de gênero, antes criminalizada de forma genérica.

A Lei não nasceu da questão pontual de Maria da Penha, mas da soma de tantas lutas e de tantas mulheres que perderam suas vidas, suas identidades e dignidade.

A violência doméstica contra as mulheres é caracterizada por qualquer ação ou conduta, baseada no gênero, que cause lesão, sofrimento físico, sexual, psicológico, dano moral ou patrimonial, no âmbito público 
ou privado (http://www.planalto.gov.br/ ccivil_03/_ato2004-2006/2006/lei/I11340. htm). Perpassa desde a humilhação, morte, tráfico de mulheres e ameaça indireta. Muito "democrática" atinge todas as camadas sociais, faixas etárias e escolaridade.

É um crime sem lócus territorial ou social e tem suas raízes na cultura machista, oriunda da nossa cultura patriarcal de dominação, onde o homem além de provedor era o dono da vida e da morte das mulheres sob a sua "proteção". Relaciona-se de forma complexa com a opressão e exploração de raça, etnia, geração, classe social, orientação sexual e está presente praticamente em todas as culturas.

A prática dessa violência está disseminada em nossa sociedade e se legitima em traços culturais de nosso país inerentes a desigualdade social e na cultura da impunidade. Quando se diz que existe a cultura da impunidade estamos salientando que a sociedade e o aparelho do Estado estão de diferentes maneiras contaminados por ela, se o Estado radicou por séculos essa prática social é o mesmo responsável pelo elo, na sua erradicação.

Nesse sentindo, é necessário compreender a violência de gênero sob uma perspectiva sociológica, já que, essa discriminação e tratamento inferior dado à mulher nada mais é do que uma verdadeira construção históricocultural.

\subsection{O circulo vicioso da violência}

Na observação diária se constata que dificilmente o homem demonstra sua agressividade em um único ato de espancamento. As agressões aparecem em um primeiro momento com insultos e ameaças. Muitas das vezes essas agressões são recíprocas, só depois o homem agride fisicamente a mulher, com socos, pontapés, com objetos.

Geralmente à fase de agressão segue-se a reconciliação: o companheiro pede perdão, promete mudar o comportamento ou finge que nada aconteceu. Nessa fase as mulheres sentem-se influenciadas a não tomar a decisão de romper com o ciclo de violência. Em inúmeros casos a mulher resolve não mais denunciar o companheiro e em outros deseja retirar a queixa, mas em geral, com o tempo as agressões recomeçam. É um circulo previsível.

Apesar da criação da Lei Maria da Penha, da criação de Delegacias especializadas para as mulheres e das secretarias da Mulher, mas da metade das mulheres agredidas não têm coragem de solicitar a ajuda. Se calam por medo, por dependência financeira ou por vergonha.

Em muitos casos a própria família das mulheres não tem conhecimento ou, quando tem, tende a ficar do lado do agressor, como se as mesmas fossem culpadas pelas agressões sofridas; elas temem apanhar de novo ou serem assassinadas, preocupam-se com a segurança de filhas e filhos. 
Quando resolvem denunciar recorrem primeiro a outra mulher, uma amiga ou familiar. A ida a delegacia só ocorre quando a gravidade da situação não mais pode ser contornada: como fraturas, ameaças aos filhos, cortes profundos ou tentativa de feminicídio.

Quando a mulher decide denunciar, a acolhida na delegacia é essencial para a conclusão do processo. Após esse passo, e, se sentirem que precisam sair dos locais de residência, devem procurar as secretarias da mulher, para que providenciem seu abrigamento junto com os filhos menores, em casas abrigo, sigilosas, onde começará o processo de reinserção no mercado de trabalho e de todo o processo de fortalecimento familiar.

Atingindo todas as classes sociais não ocorre da mesma maneira para todas. As mulheres negras, por carregarem uma herança cultural de violação de todos os direitos, originários da escravidão, sofrem mais discriminação.

As mulheres indígenas, marcadas pela exploração sexual e étnica ainda sofrem com a violação de seus direitos. Segundo o relatório da ONU em 2010, uma em cada três índias são estupradas durante a vida.

As mulheres lésbicas sofrem a discriminação em todos os espaços de poder, o que chamamos de lesbofobia e que na nossa sociedade nega diretos, na forma de intolerância social a orientação sexual apresentada.

As mulheres idosas são vitimas da violência geracional, quando aumenta a sua vulnerabilidade, é bastante e elevado o número de violência doméstica contra as mulheres idosas e regra geral ficam impunes, pois são oriundos de filhos, filhas, netos ou cuidadores e, portanto, dificilmente denunciadas por elas.

Mulheres com deficiência são mais expostas à violência doméstica e têm menor chance de conseguir a proteção por sua própria limitação.

No Brasil a violência contra a mulher é a face mais dura e cruel das desigualdades. Está entre os países com maior número de feminicidio e reconhecidamente tem um elevado índice de ocorrências de ameaças e agressões contra as suas cidadãs, com cerca de 2 milhões de casos de violência doméstica, familiar e sexista, por ano.

É a maior causa de morte e deficiência entre mulheres de 16 a 44 anos, muito mais que o câncer ou acidente de transito: www.ipas. org.br.

Corrobora com a magnitude desses fatos a pesquisa da Sociedade Mundial de Vitimólogia, realizada em 54 países e junto a 138 muIheres, que aponta para o Brasil como o país que mais sofre com a violência doméstica.

Conforme pesquisa pela fundação Perseu Abramo, em $200143 \%$ da mulheres pesquisadas assumiram ter sofrido violência doméstica e $84 \%$ dos homens pesquisados 
assumiram já terem agredido fisicamente a mulher, companheira ou namorada. Essa pesquisa também revelou o chocante dado que a cada 15 segundos uma mulher á agredida no país, ou seja, a cada dois minutos, oito mulheres são violentamente agredidas no Brasil.

Em 2010 a mesma Fundação, em parceria com o Serviço Social do Comercio (SESC), revela uma redução dessa estatística: a cada 24 segundos uma mulher é espancada, ou seja a cada 2 minutos, cinco mulheres são espancadas.

Somente em 2010, depois do advento da Lei Maria da Penha, a violência caiu pra $34 \%$, sendo um mecanismo de relevância para ordenamento jurídico brasileiro, responsável, juntos com os órgãos de defesa à mulher, pelo combate à violência de gênero.

\section{Uma visão sociológica sobre a violência doméstica: a contextualização da mulher no cenário social e jurídico}

A mulher sempre foi descriminada por sua condição frágil, e essa descriminação trouxe algumas consequências de cunho social, como por exemplo, a subordinação da muIher ao homem. Essa descriminação se deu através de uma construção verdadeiramente histórica e cultural, onde a mulher precisa ser subordinada as determinações de seu

* Das Lutas à Lei, 2011-Secretaria da Mulher de Pernambuco. marido e, até biblicamente, diz-se que o homem é o cabeça da casa, devendo, então, a mulher a ele se submeter.

Sem dúvidas a mulher sempre exerceu limitadamente sua liberdade, uma vez que ficava confinada na obrigatoriedade de cuidar do lar, enquanto o homem podia viver livremente, eram dois mundo completamente distintos, pois de um lado havia um mundo de domínio que era do homem e do outro, um mundo submisso, esse pertencia as muIheres.

A história da submissão da mulher se dava no seio familiar, pois, quando enquanto solteira, devia obediência a seus pais e irmãos mais velhos, e quando casavam essa obediência era transferida para seu marido. Havia casos em que o homem, em caso de morte, deixava escolhido o próximo marido da sua mulher, em outros, havendo o falecimento do marido, a mulher também estava condenada à morte, com intuito de servi-lo até em outro plano (Silva, 2008).

Pode-se dizer que diante desse cenário nasceu a violência doméstica, obviamente que, se a mulher era criada para obedecer o homem, tudo que este fazia era correto, inclusive usar de violência contra sua própria muIher, podendo aquela ser sexual, psicológica, emocional, etc.

Para Bassanezi (2006, p. 8): "Muito se escreveu sobre a dificuldade de se construir a 
história das mulheres, mascaradas que eram pela fala dos homens e ausentes que estavam do cenário histórico".

A fala da autora traduz a trajetória da muIher para conseguir erguer-se e ser dona do próprio eu, da sua vida, para exercê-la com liberdade e autonomia.

Silva (2008) afirma que:

À mulher não era permitido estudar e aprender a ler. Nas escolas, administradas pela igreja, somente thes eram ensinadas técnicas manuais e domésticas. Esta ignorância lhe era imposta de forma a mantê-la subjugada desprovendo-a de conhecimentos que the permitissem pensar em igualdade de direitos. Era educada para sentir-se feliz como "mero objeto» porquanto só conhecia obrigações.

Era assim que a mulher costumava ser tratada, um verdadeiro objeto nas mãos da sociedade, da igreja e dos maridos, onde suas obrigações se reduziam às domésticas, dando margem a uma exclusão intensa no âmbito social, histórico e emocional.

Na legislação brasileira a mulher foi ganhando força com o advento da Constituição Federal de 1924, quando se previu a possibilidade da mulher estudar temas diversos das permitidas outrora, porém, somente no século XX foi que a mulher passou a poder estudar em salas mistas, onde tinham homens e mulheres.
Aos homens era dado o poder de castigo às mulheres e filhos e estas, em contrapartida, não podiam pratica atos sem consentimento marital, tinha que se calar diante do abuso de autoridade que o homem exercia sobre ela, só passando a ter maior autonomia no ano de 1890, quando houve a implantação do regime republicano no Brasil em que o poder patriarcal foi mantido, todavia, com menos rigor e de forma mais suave (Silva, 2008).

No Código Civil Brasileiro de 1916 houve proteção a alguns princípios considerados conservadores e que mantinham o homem superior em relação à mulher, como por exemplo em caso de divergência de opiniões entre pai e mãe, era estabelecido que o desejo do pai prevalecesse.

Assim determinava o artigo 186 CCB/1916 (Código Civil Brasileiro de 1916): "Discordando eles entre si, prevalecerá a vontade paterna, ou, sendo o casal separado, divorciado ou tiver sido o seu casamento anulado, a vontade do cônjuge, com quem estiverem os filhos". Legalmente, a prevalência de um sobre o outro era permitido, assim, pode-se dizer que, juridicamente, não era respeitado o principio da igualdade. Mas esse artigo é um exemplo das muitas arbitrariedades que eram previstas no CCB/1916.

Todavia, com o advento do Estatuto da MuIher, em 62, o CCB/1916, sofreu modificações relevantes, assim afirma Silva que: 
Trinta anos após, com o advento da Lei no 4.121/62 (Estatuto da Mulher Casada) nosso Código Civil sofreu significativas mudanças. O artigo 393 que retirava da mulher o pátrio poder, em relação aos fiIhos do leito anterior, quando contraísse novas núpcias, teve sua redação alterada proclamando que a mulher não mais perderia os direitos do pátrio poder quando contraísse novas núpcias. O artigo 380 que dava o exercício do pátrio poder ao marido e somente na falta deste à mulher, concedeu o exercício do pátrio poder a ambos os pais, prevalecendo a vontade do homem no caso de discordância do casal, ressalvado à mãe o direito de recorrer ao juiz para solução da divergência (2008).

Sem dúvida alguma essa foi um dos grandes avanços pertinentes à mulher, uma vez que foi a partir de então que ela ganhou autonomia, podendo exercer livremente seu "poder" sobre seus filhos, dando possibilidade do rompimento conjugal sem perda do poder o poder familiar e resguardando o direito de recorrer ao Judiciário em caso de divergência de opiniões.

Essa inserção da mulher no contexto familiar e, conseqüentemente, social e jurídico, permitiu seu reconhecimento não sou como mãe, porém, deu margem para que pudesse ter um redirecionamento em sua vida como um todo.

Aos poucos, diante de toda a dificuldade enfrentada por mulheres, foi-se superando o estigma de que mulher era um sexo frágil, que sua missão era cuidar apenas da família e se submeter, completamente, ao homem.

Nascem então os movimentos feministas pelo reconhecimento da igualdade entre homens e mulheres, seja no âmbito familiar, laboral, enfim, indubitavelmente, o cenário mundial vê-se atento a essa questão.

A luta incessante pelo reconhecimento e busca de espaço social, histórico, fez com que juridicamente as mulheres ganhassem proteção especial, todavia, não foi fácil e esse reconhecimento.

Mas, mesmo diante de toda essa luta das mulheres em verem seus direitos acolhidos e assegurados, em possuírem os mesmo direitos e deveres do homem e emergirem de uma situação de descriminação e de condição social diferenciada, por ser mulher, não expurgou da sociedade a violência de gênero, que viola os direitos humanos e requer uma atenção especial, assunto que será tratado em ponto especifico do estudo.

O ganho imensurável que a mulher teve não se pode contabilizar, pois políticas públicas a inserem cada vez mais no convívio social, as oportunidades de emprego são quase que equivalentes para homens e mulher e por conseqüência os salários também.

Hodiernamente, a mulher é equiparada ao homem, assim, afirma a Constituição da República Federativa do Brasil em seu artigo $5^{\circ}$ que: 
Art. $5^{\circ}$. Todos são iguais perante a lei, sem distinção de qualquer natureza, garantindo-se aos brasileiros e aos estrangeiros residentes no País a inviolabilidade do direito à vida, à liberdade, à igualdade, à segurança e à propriedade, nos termos seguintes: I - homens e mulheres são iguais em direitos e obrigações, nos termos desta Constituição.

A norma constitucional, de observância obrigatória e que atinge a todos indistintamente, reforça a ideia de que a mulher precisa ser tratada de forma igualitária, porém, insta ressaltar que pontos específicos em relação àquela precisam ser observados por toda ordem jurídica, de cunho constitucional ou infraconstitucional brasileiro e internacional, como forma de garantir e assegura os direitos mais inerentes ao individuo, os direitos humanos.

A Violência contra a mulher não consegue ser entendida sem que se leve em conta a questão intrínseca de gênero. A nossa construção social, política e cultural do que é ser homem ou ser mulher, dentro dos conceitos de feminilidade e masculinidade, faz parte do nosso conceito de desigualdade e conseqüentemente de opressão.

É, portanto, uma questão relacional e societal e requer mudanças culturais. A Lei Maria da Penha pode ser vista como uma Lei predominantemente educativa, sua aplicabilidade, além de punitiva, busca o reconhecimento para os fenômenos étnicos, geracionais, de camadas sociais que são contributivos para a exacerbação da cultura de violência.

Joan Scott (1994) escreve que o gênero é designado socialmente para definir as relações entre sexos e direciona o saber sobre a diferença sexual.

História é tanto objeto da atenção analítica quanto um método de análise. Vista em conjunto desses dois ângulos, ela oferece um modo de compreensão. Vista em conjunto desses dois ângulos, ela oferece um modo de contribuição ao processo através do qual gênero é produzido.

A História nem sempre pode ser vista como um documento fidelíssimo à realidade. Oferece muito mais uma forma de compreensão do que se entende em uma determinada época ou local, sendo, desta forma, a questão do gênero foi uma produção social imposta sobre um corpo assexuado.

Segundo Saffioti (O poder do macho, 1987), a violência de gênero é tudo que tira os direitos humanos numa perspectiva de manutenção das desigualdades hierárquica existentes para haver a obediência, subalternidade de um sexo a outro. Tratase de formas de dominação permanente e acontece em todas as classes sociais, etnia e raças.

Simone de Beauvoir (O segundo sexo, 1994) estudando a mulher e seu papel social, aponta a subalternidade da mesma como uma perspectiva em que o papel feminino é 
destituído de identidade cultural, classificado como algo meramente biológico e natural. Ela recusa essa idéia social de naturalidade e aponta a desigualdade dos sexos como uma construção social dos sexos, atribuindo espaços de poder para homens e mulheres, nos quais a mulher sempre ocupa os menores espaços de empoderamento, valorização e recheia-se de subalternidade.

Essa violência, portanto, é entendida no processo de relações desiguais de gênero como forma de reprodução do controle do corpo feminino em uma sociedade sexista, tornando-se a expressão máxima da violação dos direitos humanos das mulheres.

Destaca-se, assim, o fenômeno como um enfrentamento de problemas mais amplos como: saúde, educação, assistência social, segurança pública, cultura, justiça entre outros; no sentido de dar conta da complexidade da violência e garantir a integralidade da atenção àquelas que vivenciam tal situação. Processo multifacetado, de raízes históricas e culturais, obriga ao Estado, para tentar erradicá-lo, uma abordagem intersetorial e multidimensional.

Por sua complexidade exige um trabalho de costura e identificação de aspectos estruturais e conjunturais da realidade.

O enfrentamento da violência contra as muIheres tem início com o movimento feminista, inicialmente propondo a transformação das relações desiguais de poder entre os gêneros, exigindo o direito de serem donas de suas vidas e de seus corpos. Foi uma luta contra a injustiça social.

Mas, efetivamente, é a partir da revolução francesa, final do século XVIII, que a presença da mulher em espaços públicos se torna mais fortalecida.

Neste momento destaca-se a figura de Olympe Gouges, feminina e revolucionária, escritora e jornalista que reivindicou direitos políticos e civis, para o seu sexo. Após escrever A Declaração dos Direitos das Mulheres e da Cidadã, foi condenada a morte. Hoje nos estarrece que seu crime, punido com a morte, foi apenas ter nascido mulher e lutar por igualdade de gênero.

Nos últimos séculos as mulheres lutaram por seus direitos, em todo o mundo. Nessa construção houve grandes momentos e também períodos de descontinuidade e retrocesso.

Essa luta pode ser dividida em dois grandes momentos: da Revolução Francesa (1789) até a Segunda Guerra Mundial (1939) onde se buscou o conhecimento, direitos políticos e inserção no mercado de trabalho, centrada no comportamento masculino, inibidor do avanço social das mulheres.

O Segundo momento se instala por volta de 1960 e se prolonga até nossos dias e é pautado pelo direito mais íntimo, que é deliberar sobre a sua sexualidade, seu corpo e sua vida reprodutiva. Nesse momento o Estado 
começa a ouvir a castração e violência acontecidas no espaço doméstico é, também, é nesse momento que se decide acompanhar cada política pública voltada às mulheres com grandes slogan feministas, como por exemplo: "O MEU CORPO ME PERTENCE E O PRIVADO É POLÍTICO”.

Em 1980, o Brasil, liderado pelos movimentos feministas, formula políticas públicas para as mulheres em favor da igualdade de gênero, criando conselhos de direito e oportunizando o processo de mudança no Brasil.

Ainda na década de 80 o feminismo voltou-se para a ONU e centrou-se nas conferências públicas e nos planos visando a igualdade de direitos entre homens e mulheres.

Em 1975 é realizada pela ONU a primeira conferência mundial para as mulheres e em 1979 a assembléia das Nações Unidas adota a Convenção sobre a Eliminação de todas as formas de Discriminações, sobre as mulheres.

No Brasil, no que diz respeito ao enfrentamento da violência contra a mulher, a Lei 11.340/2006-LEI MARIA DA PENHA, foi a resposta mais objetiva às demandas feministas, por segurança. É o reconhecimento pelo Estado de que o problema que afeta a mulher é sexista não é de natureza privada, que não diz respeito ás relações afetivas.

Todavia é matéria de interesse e responsabi- lidade de uma sociedade e, portanto, objeto de intervenção direta do ESTADO*.

\section{Eixos estruturantes da política nacional de enfrentamento à violência contra as mu- Iheres}

O combate a violência contra as mulheres compreende a eficácia no cumprimento da Lei. Com ações punitivas estabelecendo o cumprimento das normas penais que garantam a responsabilização dos agressores. No âmbito da política nacional a criação de Varas Especializadas de Violência doméstica e familiar contra a mulher. Na garantia dos Direitos Humanos das mulheres a política deverá garantir a recomendação prevista nos tratados Internacionais, especialmente as contidas no tratado de Belém do Pará. Nesse eixo a garantia do empoderamento da muIher deve ser fortalecido, junto com o acesso à justiça e o resgate das mesmas, como sujeitos de direito.

No eixo assistência deve garantir o atendimento humanizado e qualificado às vitimas de violência domestica, por meio de formação continuada aos agentes públicos, da criação de casas abrigo, centros de referencia, serviços de responsabilização, ressocialização do agressor, Defensoria e Juizados de Violência Doméstica, fortalecimento de rede de atendimento. Para e eficiência e eficácia é fundamental o monitoramento das ações de enfrentamento à violência.

\footnotetext{
* Das lutas à Lei. Uma contribuição das mulheres a erradicação da violência-2011-Secretaria da Mulher do Estado de Pernambuco.
} 
1) Prevenção: ações educativas que interfiram nos padrões sexistas;

2) Assistência: fortalecimento da rede de atendimento e capacitação de agentes públicos;

3) Enfrentamento e combate: ações punitivas e cumprimento da Lei Maria da Penha;

4) Acesso e garantia de direitos: cumprimento da legislação nacional internacional e iniciativas para empoderamento das mulheres.

\section{Coceituando a rede de atendimento}

Os governos Federal, Estadual e Municipal possuem o papel que deve ser desempenhado na prevenção e combate à Violência Doméstica, todavia ainda existe uma desarticulação entre os entes. A rede surge como uma forma de unir esses poderes, evitando a fragmentação dos serviços. O Conceito de rede refere-se a atuação articulada: serviços governamentais, instituições e comunidade, melhorando a condição do atendimento.

\begin{tabular}{|l|}
\hline Centros de Referencia de Atendimento á Mulher; \\
\hline Núcleos de atendimento á Mulher; \\
\hline Casas Abrigo; \\
\hline Casas de acolhimento provisório; \\
\hline Delegacias Especializada de Atendimento á Mulher; \\
\hline Delegacias Comuns; \\
\hline Policias Civil e Militar; \\
\hline Instituto Médico Legal; \\
\hline Defensoria da Mulher; \\
\hline Juizados de Violência doméstica; \\
\hline Central de atendimento à mulher- disque 180; \\
\hline $\begin{array}{l}\text { Ouvidoria da Mulher da Secretaria de Políticas Públicas para } \\
\text { a Mulher; }\end{array}$ \\
\hline $\begin{array}{l}\text { Serviço de saúde voltado ao atendimento aos casos de } \\
\text { violência domestica e sexual; }\end{array}$ \\
\hline Postos de atendimento Humanizado nos aeroportos; \\
\hline Núcleo da mulher da casa do imigrante. \\
\hline
\end{tabular}

Existe uma rota critica, que a mulher em situação de violência percorre.

São várias portas de entrada, no âmbito do governo a Rede de Atendimento à Mulher em situação de Violência e composta pelos seguintes serviços:

\section{Garantia e aplicabilidade da Lei Maria da Penha: em busca da igualdade}

Difundir a Lei e os instrumentos de proteção aos direitos das mulheres, junto com a ampliação dos serviços especializados de atendimento à mulher vítima de violência doméstica, são formas de garantir à cidadã o acesso à justiça, com segurança.

Devendo esta segurança abranger os direitos sexuais, enfrentamento a exploração sexual e o tráfico de mulheres, garantia da autonomia das mulheres em situação de violência e ampliação dos seus direitos.

A Lei Maria da Penha foi, indubitavelmente, o marco inicial, do Brasil, para o combate ferrenho à violência de gênero.

No Brasil, quando são instituídas as políticas públicas para as mulheres, buscando a igualdade entre gêneros são também trabalhadas através do empoderamemnto, a profissionalização e cidadania dessas mulheres. Essas políticas têm a finalidade de reparação de desigualdades que vieram, ao longo do tempo e através de um processo histórico cultural, negar direitos. 
São aspectos culturais profundos, que criaram um grande hiato entre os direitos de homens e mulheres. São ações de uma complexidade tão grande e focadas na idéia que os grupos sociais, por possuírem necessidades diferenciadas, exigem políticas específicas.

No Estado de Pernambuco, especificamente, as mulheres constituem a maioria da população. São diferenciadas por etnia, classe social, geracional, educacional e há pelo menos ha 450 anos foram legalmente privadas de exercerem a maioria de seus direitos políticos, econômico e civis, em relação aos homens, entretanto, são culturalmente responsáveis por todas as tarefas da vida reprodutiva.

Pernambuco, como Estado modelo de implantação de políticas públicas para as muIheres, no Brasil, conta hoje sua rede com 145 organismos decorrentes da visão governamental, que em 2007 criou, no aparelho do Estado, a Secretaria da Mulher do Estado de Pernambuco, momento fundamental de mudança de comportamento social; inaugurando, assim, ações de promoção e reparação dos direito das mulheres, em diversas áreas. Hoje essa iniciativa afirma a política de entender a democracia como regime político determinado a incluir no desenvolvimento setores anteriormente excluídos.

Passados sete anos, o Estado, através dos organismos de políticas publicas para as muIheres, espalhados em todas as suas regiões, tem contribuído de forma impar para a construção de um novo tempo, tendo a Secretaria da Mulher do Estado de Pernambuco, em 2012 recebido da ONU o prêmio de promoção de inclusão de gênero no serviço público. $\mathrm{Na}$ atualidade as mulheres brasileiras já têm a chance de ter uma realidade diferenciada no mercado de trabalho, quando identifica-se que mais de $70 \%$ da população feminina são provedoras de seus lares. Comparativamente há dez anos, hoje as mulheres ocupam cargos de destaque, são titulares de crédito urbano e rural e são maioria nas instituições universitárias. No Estado de Pernambuco, no mundo do trabalho produtivo remunerado, as mulheres têm se colocado diante de seus grandes desafios: garantir acesso a todos os postos de trabalho, independente da natureza da atividade, equiparar a sua remuneração e se qualificar profissionalmente.

Apesar de todas essas conquistas sabe-se que ainda se tem muito a construir no campo da igualdade de gênero.

Para isso os organismos de políticas públicas para as mulheres, ao serem criados estabelecem uma rede que produz criticas, autocríticas, mas principalmente cria valores para mudar as relações patriarcais e a visão machista, que historicamente determinam as relações desequilibradas de poder entre homens e mulheres (Cristina Buarque-Anuário da Secretaria da Mulher de Pernambuco-2012). 
A missão dos organismos de políticas para as mulheres é promover os direitos das muIheres, no ESTADO e a busca é pela redução da desigualdade de gênero, promoção das políticas públicas e articulação com outros atores organizados.

Tendo como função precípua o enfrentamento à violência doméstica, preocupa-se em trabalhar, na sua estrutura funcional, com a produção do conhecimento, como forma preventiva e promoção dos direitos das muIheres, nas áreas de trabalho e renda, saúde, educação, cultura , lazer e justiça, como forma de empoderamento e reparação.

Em 2012 houve um significativo avanço nas relações entre os órgãos que trabalham com a Lei Maria da Penha (Lei 11.340/2006) em Pernambuco, coordenado pela Secretaria da Mulher do Estado, que aglutina a Secretaria de Defesa Social, com as delegacias da MuIher (DPMUL), a Policia Militar, com o pacto pela vida, no seu recorte de gênero, o Tribunal de Justiça, com varas especializadas em violência doméstica, as 145 Secretarias e Coordenadorias da Mulher, Departamento de Homicídios e proteção à pessoa, Secretaria Estadual de Saúde, Secretaria de Desenvolvimento Social e Direitos Humanos, Defensoria Pública e Ministério Público.

Promovendo ainda campanhas educativas e preventivas, a rede de atendimento à muIher do Estado de Pernambuco, se configura como a mais estruturada do Brasil, tendo re- duzido em $34 \%$ a violência doméstica letal nos últimos seis anos.

Contando com uma rede de acolhimento, através dos Centros de Referências de Atendimento à Mulher (CRAM) e rede de abrigamento para as mulheres com risco eminente de morte e seus filhos menores, tem oferecido o apoio necessário para aquelas que querem romper com esses ciclo de violência.

Oferecendo mais de 130 programas e campanhas de prevenção, reparação, empoderamento e conhecimento de direitos, a rede de organismos municipais para políticas para as mulheres, juntamente com a Secretaria da Mulher do Estado de Pernambuco é referencia na busca da mudança da cultura patriarcal, sexista e machista para uma cultura igualitária de gênero.

\section{CONCLUSÃO}

O presente estudo teve como finalidade fazer uma análise da evolução social e jurídica da mulher, levando em consideração a violência que esta sofreu e sofre ao longo de tanto tempo. Assim como, trouxe a tona um dos instrumentos de combate, no Brasil, da violência de gênero, que é a Lei Maria da Penha, intitulada assim em razão da violência domestica sofrida por Maria da Penha e culminou na evolução legislativa quanto à violência de gênero.

Insta salientar que o combate a violência de 
gênero, algo discutido e vivenciado ao longo de muitos e muitos anos, não se deu de forma rápida, houve um longo caminho percorrido, inclusive manifestações de cunho internacional que cobraram do Brasil o enfrentamento a esse tipo de violência. Somente em 2006 publicou-se a Lei Maria da Penha.

A Lei Maria da Penha busca enfrentar a violência de forma mais impositiva, trazendo a possibilidade de uma punição mais severa para àqueles que cometem a violência de gênero. É o que tem acontecido, por exemplo, no estado de Pernambuco-Brasil, onde tem se garantido sua eficácia bem como sua aplicabilidade.

Porém, sabe-se que muito há que se fazer para conseguir uma aplicabilidade plena e uma eficácia realmente que abranja todo o território nacional, pois pesquisas têm demonstrado que mesmo com o advento da lei de combate à violência de gênero os feminicidios ainda ocorrem com muita freqüência em todo o território nacional, o que faz-se acreditar que é necessários mais políticas públicas que ajudem na prevenção da violência doméstica, o que permitirá, realmente, uma eficácia ilimitada.

O enfrentamento à violência contra a mulher insere o combate a exploração sexual, tráfico de mulheres, garantia da autonomia das muIheres em situação de violência e ampliação dos seus direitos, premissas que devem ser protegidas e garantidas pelo Estado Democrático de Direito.

\section{REFERÊNCIAS}

Bassanezi, C. (2006). História das Mulheres no Brasil. São Paulo: Contexto. 8a ed. Disponível em: http://books.google.com.br/ books?hl=pt PT\&|r=\&id=8KgRI5ZvX8wC\&oi $=$ fnd \&pg=PA7\&dq=historia + da + mulher \&ots $=$ =Nr1OSEZJTN\&sig=Dyu8w4Fb9nPxliBrL53B| J9Um6U\#v=onepage\&q=historia\%20da\%20 mulher\&f=false

Beauvior, S. O segundo sexo. São Paulo: Ed. Difusão Européia de Livros. Tradução de Sergio Milliet.

Bobbio, N. (1992). A era dos Direitos. Tradução de Carlos Nelson Coutinho. Rio de Janeiro: Elsevier. 19a Reimpressão.

Bonavides, P. (1997). Curso de Direito Constitucional. 7ạ ed. Revista e ampliada. São Paulo: Ed. Malheiros.

Buarque, C. (2012). Anuário da Secretaria da Mulher de Pernambuco.

Código Civil Brasileiro de 1996.

Convenção Interamericana para Prevenir, Punir e Erradicar a Violência Contra a Mulher, "Convenção de Belém do Pará". Disponível em: http://www.cidh.oas.org/basicos/ portugues/m.Belem.do.Para.htm

Da Silva, R. (2008). Evolução histórica da mulher na legislação civil. http://ditizio.ecn. br/adv/txt/ehlc.pdf. Acessado em 17 de setembro de 2013. 
Lenza, P. (2011). Direito Constitucional Esquematizado. 15a edição. São Paulo: Ed. Saraiva.

Lenza, P. (2012). Direito Constitucional Esquematizado. 16a edição. São Paulo: Ed. Saraiva.

Piovesan, F. (2004). Ações Afirmativas da Perspectiva dos Direitos Humanos. Rio de Janeiro. Disponível em: http://www.scielo.br/ pdf/cp/v35n124/a0435124.pdf

Piovesan, F. (2013). Pela Implementação da Lei Maria da Penha: A luta das mulheres pelo direito a uma vida sem violência. Disponível em: http://www.compromissoeatitude.org. $\mathrm{br} /$ pela-plena-implementacao-da-lei-mariada-penha-a-luta-das-mulheres-pelo-direitoa-uma-vida-sem-violencia-por-flavia-piovesan/

Saffioti, S. (1987). Bongiovani lara Heleith. O Poder do Macho. Ed. Moderna.
Scott, J. (1994). Deconstruir igualdad -versus - diferencia: uso de la teoría posestructuralista para el feminismo. Revista Feminaria, (13), Buenos Aires.

Silva, J. A. da (2007). Ação Popular Constitucional: Doutrina e Processo. 2a Ed. Revista e ampliada. São Paulo: Ed. Malheiros.

Tavares, A. R. (2008). Curso de Direito Constitucional. 6a edição. São Paulo: Ed. Saraiva.

Tirado, M. (2013). Comercio Sexual. Segunda edición. Bogotá: ILAE.

Wald, A. (2009). Direito Civil, Direito de Família. Ed. 17ạ. São Paulo: Ed. Saraiva.

www.ipas.org.br. Acessado em 23 de setembro de 2013. 